\title{
O DESIGN INCLUSIVO NO BRASIL: SEU ENSINO NOS CURSOS DE GRADUAÇÃO EM DESIGN
}

\section{INCLUSIVE DESIGN IN BRAZIL: ITS TEACHING IN GRADUATION COURSES IN DESIGN}

\author{
Danila Gomes ${ }^{1}$, M.Sc. \\ Manuela Quaresma², D.Sc \\ (1) LEUI | Laboratório de Ergodesign e Usabilidade de Interfaces - PUC-Rio \\ e-mail: danilagomespe@gmail.com \\ (2) LEUI | Laboratório de Ergodesign e Usabilidade de Interfaces - PUC-Rio \\ e-mail:mquaresma@puc-rio.br
}

Design Inclusivo, Ensino do Design, Ergonomia

$\mathrm{Na}$ investigação feita com professores que afirmam ensinar o Design Inclusivo e com designers que declaram conhecê-lo, notaram-se contrapontos quanto à teoria e à prática ensinada e entendida por eles. Portanto, ao decorrer deste artigo encontram-se o esclarecimento do real objetivo desta abordagem como parte da busca pela sua adoção.

\section{Inclusive Design, Design Teaching, Ergonomics}

In the research done with teachers who claim to teach Inclusive Design and with designers who declare to know it, counterpoints have been noted regarding the theory and practice taught and understood by them. Therefore, in the course of this article are the clarification of the real objective of this approach as part of the search for its adoption.

\section{Introdução}

Este artigo é parte de uma pesquisa de mestrado intitulada: A aplicabilidade do Design Inclusivo em projetos de Design. O problema central encontrado entorno deste tema é a ausência de produtos inclusivos no mercado brasileiro. À vista disso, a pesquisa referida partiu da hipótese de que a ausência do ensino da prática dessa abordagem faz com que designers formados não saiam aptos a adota-la profissionalmente. Então, buscou-se através de técnicas de investigação traçar um panorama do ensino e da prática do Design Inclusivo no Brasil e contrapor este contexto com a realidade dos profissionais estrangeiros que $o$ adotam.
A partir disso, foi possível reconhecer adversidades, a começar com a falta de compreensão da filosofia dessa abordagem projetual por muitos dos designers respondentes. Neste artigo constam alguns resultados advindos de um questionário online aplicado com professores/pesquisadores, profissionais de mercado, professores/pesquisadores e profissionais de mercado, pesquisadores e estudantes atuantes na área do Design no Brasil. Serão expostos a seguir os equívocos encontrados no ensino e na compreensão do Design Inclusivo, além de apresentar também um breve esclarecimento do real objetivo dessa abordagem como uma das soluções para os equívocos encontrados.
Realização:

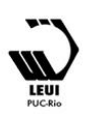




\section{$16^{\circ}$ \\ ERGODESIGN USIHC CINAHPA}

compreensão das reais necessidades de pessoas com diferenças funcionais ${ }^{1}$, que diante de barreiras são impedidas de viver com mais autonomia. Não obstante, veremos a seguir que a filosofia do Design Inclusivo busca um olhar mais amplo e realista, ele crê que todos os seres humanos são diferentes em limitações e habilidades. Portanto, cabe afirmar que dificuldades funcionais podem estar presentes no cotidiano de qualquer pessoa, ou seja, este não é um problema vivenciado somente por pessoas com deficiência, mas por todos nós. Então, é válido reforçar essa percepção com uma frase fundamental para o entendimento dessa filosofia: "inclusão é para todos porque somos todos diferentes" [DEFICIENTE CIENTE, 2015)

Design Inclusivo, também conhecido como 'Design para todos' e 'Design Universal', procura evitar a necessidade de ambientes e produtos exclusivos para as pessoas com diferenças funcionais, no sentido de assegurar que todos possam utilizar livremente produtos e ambientes. A proposta é ampliar o público destinatário do projeto, considerando características, vivências e necessidades tanto dos grupos dominantes como dos minoritários, ou seja, favorecendo a diversidade funcional natural e contribuindo para melhorias da qualidade de vida para todos.

Este artigo reforça o pensamento de diversidade como ordem natural da humanidade e a igualdade de direitos como processo lógico e obrigatório. Reconhecemos a filosofia do Design Inclusivo como fonte de esclarecedora de que limitações e habilidades são comuns a todos nós e que soluções inclusivas nos beneficiam em praticidade.

Portanto, as pessoas com diferenças funcionais são naturalmente incluídas nesta abordagem de projeto, por serem fontes inspiradoras para a prática da usabilidade.

\footnotetext{
${ }^{1} \mathrm{O}$ termo 'pessoas com diferenças funcionais' se refere às pessoas que apresentam dificuldades atípicas temporárias ou permanentes que são contornadas pelo reaprendizado das funções alteradas ou perdidas, mesmo tendo o auxílio de instrumentos como próteses e órteses. Encaixam-se nesse grupo pessoas com deficiência ou não, como idosos, pessoas com obesidade, gestantes etc.
}

$16^{\circ}$ Ergodesign - Congresso Internacional de Ergonomia e Usabilidade de Interfaces Humano Tecnológica: Produto, Informações Ambientes Construídos e Transporte

$16^{\circ}$ USIHC - Congresso Internacional de Ergonomia e Usabilidade de Interfaces Humano Computador

CINAHPA | 2017 - Congresso Internacional de Ambientes Hipermídia para Aprendizagem.

Parece claro o objetivo desta abordagem, mas muitos profissionais não o conhecem de fato. $\mathrm{Na}$ pesquisa feita notou-se que a maior fonte de conhecimento do Design Inclusivo é o meio acadêmico. Sendo assim, cabe questionar: como e o que está sendo ensinado pelos professores? A seguir, alguns resultados e conclusões da pesquisa exploratória que fundamentou a elaboração do questionário on-line e alguns resultados do questionário.

\section{Pesquisa exploratória: visão preliminar do ensino do Design Inclusivo por professores do curso de graduação em Design}

Dorneles [2011, p. 148] desenvolveu sua tese de doutorado sobre o ensino do Desenho Universal nos cursos de graduação em Arquitetura e Urbanismo no Brasil e percebeu a escassez do ensino nesta área no país. A autora afirma que "o desenvolvimento dessa competência deve ser realizado nas universidades durante a formação profissional dos alunos". Dorneles afirma que o ensino do Desenho Universal ainda é um desafio a professores não só do curso de Arquitetura, mas também de diversos outros cursos no Brasil, como: Design e Tecnologia da Informação.

Assim sendo, a fim de explorar essa questão, quatro professores do curso de graduação em Design de uma universidade do Rio de Janeiro foram entrevistados através de uma pesquisa exploratória, com o intuito de saber como são abordadas as questões de inclusão social nas salas de aula, se o Design Inclusivo é mencionado por eles e como isso é feito. As respostas reforçaram outro possível fator: a falta de conhecimento pleno do conceito do Design Inclusivo por conta dos professores.

Através de entrevistas semiestruturadas (com o termo de consentimento livre e esclarecido assinado), com a duração de aproximadamente uma hora. Os professores foram indagados quanto ao ensino no curso de graduação em Design. Inicialmente, com questões gerais como: em qual turma ministra aulas; qual metodologia de projeto
Realização:

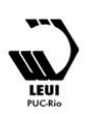




\section{$16^{\circ}$ \\ ERGODESIGN USIHC CINAHPA}

ensina e como são as fases principais do processo de projeto ensinadas por eles. Com o intuito de encaminhar a entrevista para o assunto principal, foi questionado se o entrevistado aborda as pessoas com deficiência $(\mathrm{PcD})$ na disciplina em que leciona, se a resposta fosse sim, como aborda. Foi perguntado também, aos professores que abordam as PcD em suas aulas, se seus alunos já fizeram projetos para este público e como eram estes projetos.

Em seguida, se situando no tema principal da entrevista, foi perguntado se o entrevistado já havia abordado o Design Inclusivo em suas aulas e como tinha sido feito. Neste momento, foi possível descobrir se os entrevistados conheciam realmente o Design Inclusivo e se o ensinava corretamente. Baseando-se nos depoimentos dos professores, notou-se a procura por parte dos alunos em projetar soluções destinadas às pessoas com diferenças funcionais, esta categoria de produtos se enquadra em produtos acessíveis, exclusivos para pessoas com necessidades especiais (PNE) ou PcD, não em produtos inclusivos. Para alguns professores, esta procura é frequente, mas para outros é raro pensar em acessibilidade. Nenhum dos professores entrevistados aborda o conceito e a prática do Design Inclusivo em suas aulas. Portanto, não foi levantado nenhum exemplo de projeto, orientado por eles, que seja verdadeiramente inclusivo. A seguir, veremos mais detalhadamente das informações obtidas nas entrevistas.

O Participante 1 (P1), declara que já esteve envolvido com projetos para pessoas com diferenças funcionais tanto no meio acadêmico como em trabalhos profissionais e assume se preocupar com este público principalmente em projetos de mobiliário urbano, por mais que muitos destes projetos sejam engavetados. Ainda afirma que o Design Inclusivo só é abordado em suas aulas quando o tema de projeto prevê (este tema de projeto é modificado a cada período acadêmico) ou quando o aluno trás uma oportunidade.

P1 nota a vontade que os alunos têm em trabalhar com temas que envolvam a dificuldade de uso e a acessibilidade, ele relata que isto acontece com frequência em suas aulas. Com relação ao processo projetual ensinado para o desenvolvimento de produtos, embora não tenha apresentado nenhum exemplo de projeto inclusivo orientado por ele. Contudo, cabe dizer que P1 não ensina o Design Inclusivo em suas aulas a menos que a vontade de trabalhar com esta abordagem de projeto parta de algum aluno. Notou-se que há o conhecimento do Design Inclusivo, mesmo que superficial e com pouca intimidade com o assunto.

O Participante 2 (P2) afirma abordar as pessoas com diferenças funcionais em suas aulas. $\mathrm{O}$ professor enfatiza a importância da empatia como uma etapa fundamental da pesquisa, "é você se colocar no lugar do outro para entender o que ele sente", ele desafia os alunos a se colocarem em uma situação de limitação momentaneamente para entender melhor como é a vivência de uma pessoa com diferença funcional em uma determinada situação.

P2 relata não ter uma aula exclusiva sobre Design Inclusivo, "não é dada a teoria sobre este tema, mas eu tento no briefing de projeto incluí-lo". Observa-se que este professor não ensina o Design Inclusivo em suas aulas, o conceito deste é inserido sutilmente em suas orientações de projeto, sem que o aluno tome conhecimento de fato dessa abordagem.

O Participante 3 (P3) nunca abordou as pessoas com diferenças funcionais em suas aulas. P3 relata não ter pensado em acessibilidade ou no Design Inclusivo antes. Acredita que designers não gostam de restrições, pois "podem limitar a criatividade", segundo ele, isto explica o desinteresse em projetar para as pessoas com diferenças funcionais, ou até mesmo pelo Design Inclusivo.

O Participante 4 (P4) alega que a abordagem de das diferenças funcionais depende do projeto que $\mathrm{o}$ aluno esteja desenvolvendo, ou seja, essa abordagem específica vai depender da demanda do projeto. O professor diz ensinar uma metodologia híbrida e que esta deixa as portas abertas para trabalhar ou não com a acessibilidade, e afirma que quem vai dizer o que deve ser aplicado no projeto para que haja acessibilidade é o orientador. Portanto, para trabalhar com a acessibilidade no

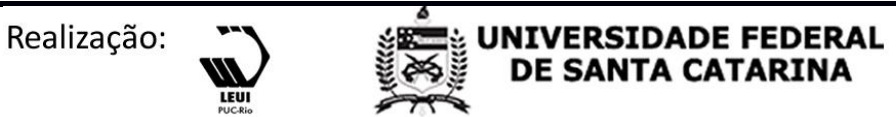




\section{$16^{\circ}$ \\ ERGODESIGN USIHC CINAHPA}

projeto, depende não só do interesse do aluno e da demanda de projeto, depende também do interesse e do conhecimento do orientador. P4 não ensina o Design Inclusivo em suas aulas e acredita que a nomenclatura do Design Universal (Design Inclusivo) é muito vaidosa e ampla, pois "um produto que é legal para uma pessoa no Brasil pode não agradar uma pessoa em outro país". Ele acredita que não tem como dissociar a questão cultural dos projetos. E reforça, "eu não acredito que o Design Universal agrade 'gregos' e "troianos"; "qualquer projeto pode ter acessibilidade, mas discordo quando diz que atenderá a todos".

P4 baseado em sua vivência como professor e profissional de mercado afirma: "eu comparo essa expressão de Design Universal a um modismo, assim como surgiu o Fun Design e o Design Emocional. Modificar um local para atender um público pequeno em um evento esporádico pode necessitar de custos muito mais elevados do que modificá-lo para a maioria das pessoas terem acesso. Querer que todo e qualquer projeto seja universal é uma utopia, tudo vai depender do contexto do projeto." Portanto, além de não abordar o Design Inclusivo em suas aulas, percebese que o conceito desta abordagem não está claro para este professor. Ele expõe nitidamente o seu pensamento relativista com a adesão de projetos que incluem as diferenças funcionais.

Todos os professores lecionam em disciplinas de projeto. Nenhum dos quatro professores cita o Design Inclusivo em suas aulas, porém P2 incentiva os alunos a pensarem nas diferenças funcionais ao projetarem. P1 e P2 já vivenciaram a elaboração de projetos com a abordagem de pessoas com diferenças funcionais, mas $\mathrm{P} 3$ e $\mathrm{P} 4$ nunca projetaram com esse pensamento.

Contudo, percebe-se o equivoco e o desconhecimento do Design Inclusivo por alguns professores e, o interesse dos alunos em buscar soluções para as diferenças funcionais.

Efetivamente, nota-se a ausência do ensino do conceito e da prática dessa abordagem de projeto por todos os professores entrevistados. Faz-se necessário que, primeiramente seja esclarecido o $16^{\circ}$ Ergodesign - Congresso Internacional de Ergonomia e Usabilidade de Interfaces Humano Tecnológica: Produto, Informações Ambientes Construídos e Transporte

$16^{\circ}$ USIHC - Congresso Internacional de Ergonomia e Usabilidade de Interfaces Humano Computador

CINAHPA | 2017 - Congresso Internacional de Ambientes Hipermídia para Aprendizagem.

real objetivo do Design Inclusivo e como ele se configura na prática projetual para que esta realidade não se pendure nesse grupo de professores e em realidades similares de outras diversas universidades brasileiras.

\section{0 ensino do Design Inclusivo nos cursos brasileiros de graduação em Design}

De maneira mais ampla, buscou-se saber se a realidade encontrada na pesquisa exploratória é comum a outros professores. Divulgou-se um questionário on-line criado na plataforma Eval\&Go, através de e-mail e via facebook. O mesmo obtive-se 477 respondentes, porém apenas $61 \%$ deles responderam todo o questionário. Do total de participantes, $86 \%$ atuam no campo do Design, 4\% em Arquitetura, 2\% em Engenharia, $1 \%$ em Publicidade/Propaganda e 7\% atuam em outras áreas. Nesta pesquisa, buscou-se ater apenas nas respostas advindas dos perfis atuantes no campo do Design.

Notou-se que há o conhecimento e o ensino do DI nos cursos de graduação em Design no nível quantitativo obtido. Portanto, a realidade vivida por muitos professores é diferente da relatada no início deste artigo, vivenciada pelos professores entrevistados. $86 \%$ dos professores que responderam o questionário afirmaram conhecer o Design Inclusivo e apenas 14\% declararam não o conhecer. Dos professores que disseram conhecer $51 \%$ deles afirmaram ensinar ou já ter ensinado o Design Inclusivo no curso de graduação em Design. Portanto, nota-se que um pouco mais da metade ensina essa abordagem, pode-se considerar então que o ensino é factual.

Com base nas respostas dos professores, o Design Inclusivo vem sendo ensinado há aproximadamente 20 anos por alguns professores, mas para muitos essa é uma abordagem recentemente adotada em suas aulas, há 5 anos. Com o intuito de saber como o Design Inclusivo está sendo ensinado por estes professores questionou-se em quais disciplinas e em qual habilitação do curso ele o ensina ou o ensinou. A habilitação do curso de graduação em que é mais ensinado o Design Inclusivo é Projeto de Produto e 


\section{$16^{\circ}$ \\ ERGODESIGN USIHC CINAHPA}

no topo das disciplinas mais citadas pelos respondentes estão:

Ergonomia, citada por 29\% dos professores como uma disciplina da habilitação Projeto de Produto em que é abordado o Design Inclusivo, sendo citada também por $7 \%$ dos professores como disciplina da Comunicação Visual, 2\% dos professores ensinam na habilitação Mídia Digital e 9\% na habilitação Moda.

Projeto de Produto, citada por $23 \%$ dos professores como disciplina da habilitação Projeto de Produto em que é ensinado o Design Inclusivo.

Projeto Final/Trabalho de Conclusão de Curso, citada por $16 \%$ dos professores como disciplina da habilitação Projeto de Produto em que se ensina o Design Inclusivo, mencionada também por $2 \%$ dos professores como disciplina da Comunicação Visual e 2\% da Moda.

Projeto, mencionada por $14 \%$ dos professores como disciplina da habilitação de Projeto de Produto em que é ensinado o Design Inclusivo 7\% dos professores afirmaram ensinar o Design Inclusivo nessa disciplina na habilitação de Moda e $2 \%$ dos professores afirmaram ensina-lo nessa disciplina na habilitação de Comunicação Visual.

Nota-se a ligação do Design Inclusivo com a Ergonomia e com disciplinas relacionadas à prática projetual. A ligação do Design Inclusivo com a Ergonomia é algo pertinente da abordagem do design centrado no usuário, ou seja, da busca por conhecer o usuário, suas necessidades, a tarefa a ser exercida e a busca por tornar o envolvimento do usuário em produtos que promovem o conforto, segurança e a facilidade de uso.

Entre as metodologias mais utilizadas no ensino pelos professores respondentes que afirmaram ensinar ou já ter ensinado o Design Inclusivo em suas aulas estão: Metodologia de Baxter (1998), mencionada por $35 \%$ dos respondentes; Metodologia de Gui Bonsiepe (1984), mencionada por 26\%; Método de Löbach (1981), citado por 23\% e Metodologia de Bruno Munari (1981), mencionada por $16 \%$. $16^{\circ}$ Ergodesign - Congresso Internacional de Ergonomia e Usabilidade de Interfaces Humano Tecnológica: Produto, Informações Ambientes Construídos e Transporte

$16^{\circ}$ USIHC - Congresso Internacional de Ergonomia e Usabilidade de Interfaces Humano Computador

CINAHPA | 2017 - Congresso Internacional de Ambientes Hipermídia para Aprendizagem.

Outros processos projetuais foram citados também, como o Design Thinking, mencionado por $12 \%$ dos professores, o Double Diamond, mencionado por 7\% dos professores e Análise Ergonômica por 7\% dos professores. No entanto, apesar de ter professores que ensinam metodologias que induzem à abordagem centrada no usuário de forma mais frequente no processo, a maioria dos professores respondentes optam por ensinar metodologias mais focadas na comercialização do produto, ou seja, mais voltadas ao ganho da indústria. Um dos problemas levantados pelos profissionais estrangeiros que adotam o Design Inclusivo é o não engajamento do usuário no processo de elaboração de produtos, pois muitos profissionais acreditam que este engajamento demanda mais tempo de projeto e consequentemente mais custos. $\mathrm{O}$ contexto observado através do levantamento das metodologias mais ensinadas explica o porquê que muitos profissionais optam por um processo mais rápido, com menos envolvimento do usuário. Eles ainda estão sendo treinados a se preocuparem mais com o lucro da empresa do que com o ser humano que há de ser o usuário ou não.

De outra perspectiva, parece haver um equivoco nas respostas, a disciplina chamada Ergonomia é citada pela maioria dos professores que afirmaram ensinar o Design Inclusivo. Visto que a maioria das metodologias é voltada para as disciplinas de 'Projeto' e se desprende completamente da prática da Ergonomia, cabe aqui um novo questionamento: de que forma a prática do Design Inclusivo está sendo ensinada na disciplina 'Ergonomia'? Supostamente esse impasse ocorre porque o Design Inclusivo pode estar sendo ensinado superficialmente ou que somente o conceito está sendo passado nessa disciplina.

\section{O conhecimento do Design Inclusivo pelos designers}

A amostra selecionada para analisar o conhecimento e prática do Design Inclusivo no mercado profissional é composta por profissionais formados em Design e que trabalham neste campo de atuação. Mesmo tendo profissionais que também atuam no meio acadêmico/de pesquisa, os
Realização:

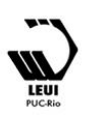




\section{$16^{\circ}$ \\ ERGODESIGN USIHC CINAHPA}

profissionais em evidência são necessariamente formados em Design. Foram obtidos nesta amostra 109 respondentes, dentre eles $40 \%$ são profissionais que atuam somente no mercado profissional e $60 \%$ são atuantes no mercado e na área acadêmica/pesquisa.

Observou-se que o conhecimento do Design Inclusivo é factual entre os designers que responderam o questionário, porém nota-se que a maioria declarou não aplicá-lo em seus projetos. Ou seja, dos $71 \%$ de designers que disseram conhecer o Design Inclusivo, apenas 29\% deles afirmaram que o coloca em prática. Isso nos mostra que por mais que existam profissionais que o desconhecem, o número de profissionais presentes no mercado que já tiveram contato com essa abordagem de projeto é significativo, porém nos leva a crer que conhecê-lo não é o bastante para aplica-lo.

Com o intuito de compreender de onde vem o conhecimento do Design Inclusivo pelos respondentes que atuam no mercado, questionou-se onde os mesmos aprenderam essa abordagem de projeto. As opções de respostas variam de acordo com a forma de atuação, ou seja, nas opções de respostas que apareciam para os respondentes que declararam atuar no mercado e na academia tinham opções como: "Por demanda acadêmica (como professor)", opção esta que não aparecia para os profissionais que só atuavam no mercado. A seguir dois gráficos com o resultado dessa questão.

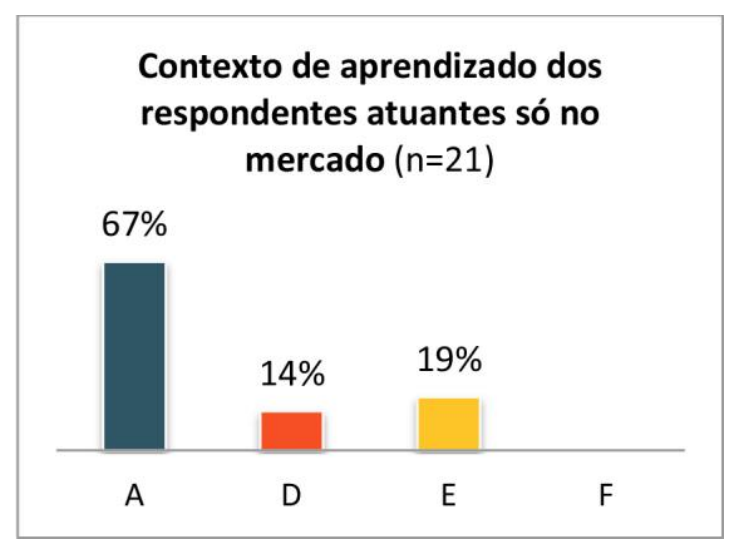

$16^{\circ}$ Ergodesign - Congresso Internacional de Ergonomia e Usabilidade de Interfaces Humano Tecnológica: Produto, Informações Ambientes Construídos e Transporte

$16^{\circ}$ USIHC - Congresso Internacional de Ergonomia e Usabilidade de Interfaces Humano Computador

CINAHPA | 2017 - Congresso Internacional de Ambientes Hipermídia para Aprendizagem.

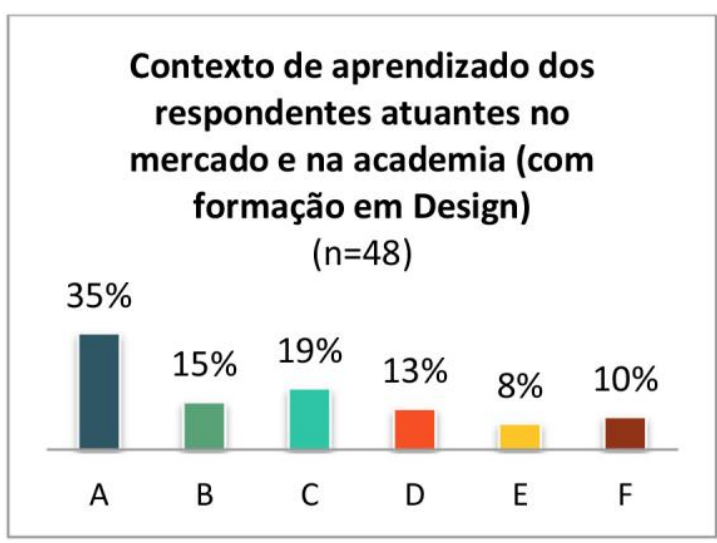

$\mathrm{A}=\mathrm{Em}$ aulas na universidade (enquanto aluno)

$B=$ Por demanda acadêmica (como professor)

$\mathrm{C}=$ Por demanda de pesquisa (como pesquisador)

$\mathrm{D}=$ Por demanda de mercado

$\mathrm{E}=$ Motivação pessoal

$\mathrm{F}=$ Outros

Gráfico 2: Contextos de aprendizado do Design Inclusivo pelos profissionais atuantes somente no mercado. Gráfico 3: Contextos de aprendizado do Design Inclusivo pelos profissionais formados em Design atuantes no mercado e no meio acadêmico. Produzidos pelo autor.

De modo geral, nota-se que a maior fonte de conhecimento do Design Inclusivo pelos designers respondentes atuantes no mercado é a universidade. Se dividir esses dados por motivação pessoal, demanda de ofício e aprendizado acadêmico, a demanda de ofício representaria $36 \%$ da fonte de conhecimento do Design Inclusivo dos dois grupos de profissionais juntos, ou seja, o ensino universitário ainda demonstra ter um peso significativo no contato com o Design Inclusivo.

Tanto para o grupo de profissionais que atuam somente no mercado quanto para os que também atuam na academia, o ensino do Design Inclusivo advindo da formação é mais expressivo do que as outras fontes de conhecimento separadamente. É possível notar também que há uma demanda de mercado em ambos os grupos mesmo que sutil. 


\section{$16^{\circ}$ \\ ERGODESIGN USIHC CINAHPA}

Se dividir o percentual em motivação pessoal, demanda de ofício e ensino universitário em cada grupo de profissionais separadamente, há uma nova percepção dos dados. No grupo de profissionais que também atuam na academia, a demanda de ofício é mais representativa do que o aprendizado na universidade enquanto aluno, representando $47 \%$ da fonte de conhecimento do Design Inclusivo. Nota-se também que a demanda como professor é um pouco maior do que a demanda de mercado. Portanto, isso reforça a ligação do Design Inclusivo com o ambiente acadêmico.

No grupo de profissionais atuantes somente no mercado, ainda que exista a demanda de ofício, o ensino acadêmico do Design Inclusivo continua sendo a maior fonte de conhecimento dessa abordagem de projeto. E nota-se também, entre estes profissionais, que a motivação pessoal, ou seja, a busca pelo Design Inclusivo é presente entre os designers que conhecem essa abordagem, mais até significativo que a própria demanda de mercado.

Com o intuito de confirmar se os profissionais que disseram conhecer o Design Inclusivo realmente compreendem o seu real objetivo, levantou-se a pergunta: o que você entende por Design Inclusivo? Dentre os 78 respondentes que declararam conhecer essa abordagem, 55 responderam esta questão. A análise foi feita observando a similaridade das respostas dos participantes com a definição do Design Inclusivo sugerida pelo Design Council [2008, apud CLARKSON et al., 2015] que diz:

"O Design Inclusivo é uma abordagem geral
para a concepção de projetos em que os
designers garantem que seus produtos e serviços
atendam as necessidades do maior público
possível, independentemente da idade ou
habilidade." [DESIGN COUNCIL, 2008, apud
CLARKSON, et al., 2015, p. 235; tradução
nossa].

Serão expostas a seguir algumas respostas que se destacaram em meio às demais.

Obtivemos respostas bem congruentes como esta: $16^{\circ}$ Ergodesign - Congresso Internacional de Ergonomia e Usabilidade de Interfaces Humano Tecnológica: Produto, Informações Ambientes Construídos e Transporte

$16^{\circ}$ USIHC - Congresso Internacional de Ergonomia e Usabilidade de Interfaces Humano Computador

CINAHPA | 2017 - Congresso Internacional de Ambientes Hipermídia para Aprendizagem.
"É aquele que permite um uso universal, seja para pessoas comuns, portadoras de necessidades especiais, idosos ou mesmo crianças. Atende diferentes necessidades, sejam elas físicas ou mesmo de cunho emocional e cultural em um determinado contexto. Pensar a inclusão é criar condições para que o 'diferente' se torne 'parte' e seja contemplado na ação. Sua intenção é promover a autonomia e o acesso facilitado por todos." Portanto, fica claro que para este respondente o Design Inclusivo busca compreender as diferentes necessidades para facilitar o uso de uma gama maior de usuários, objetivo real dessa abordagem de projeto.

Este respondente alega ter aprendido sobre o Design Inclusivo na universidade (enquanto aluno), ele declara também que o aplica (ou já o aplicou) em seus projetos e que também o ensina (ou já o ensinou) suas aulas, portanto, é um profissional de mercado e acadêmico que reconhece o real sentido do Design Inclusivo e que o põe em prática.

Este outro respondente também mostra claramente que compreende o real objetivo do Design Inclusivo, exemplificando e até mesmo expondo o limite dessa abordagem: "Projetar alguma solução (serviço, espaço, produto, gráfico) que seja passível de ser utilizada por todos, sem que eventuais limitações físicas ou outras sejam empecilho. Exemplo: calçadas que sejam naturalmente seguras para idosos, cegos, cadeirantes; entradas de prédios, banheiros que não demandem um acesso 'exclusivo' - a própria palavra já expressa que está havendo algum tipo de exclusão. Em alguns casos é difícil buscar uma solução que abrace tudo, mas... esse é o trabalho dos designers." Ele declara ter conhecido o Design Inclusivo na universidade enquanto aluno, é um profissional que atua somente no mercado e não aplica essa abordagem em seus projetos. Nota-se que este respondente compreende o que é o Design Inclusivo, mas não o aplica, isso reforça o que já foi mencionado anteriormente, conhecer o Design Inclusivo não é o bastante para coloca-lo em prática.

Não obstante, notou-se o equivoco em algumas
Realização:

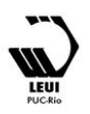




\section{$16^{\circ}$ \\ ERGODESIGN USIHC CINAHPA}

respostas como estas abaixo, que mostram a associação do Design Inclusivo com soluções para pessoas com diferenças funcionais. "Desenvolver soluções seja de interfaces e interações físicas e/ou comunicacionais com o intuito de abranger/atender e suprir necessidades práticas, funcionais, estéticas e simbólicas ao perfil de usuários que apresentam algum tipo de desabilidade física/fisiológica ou cognitiva." O respondente aponta para o perfil de usuários beneficiadores do projeto, ou seja, o público alvo da abordagem como sendo indivíduos com algum tipo de "desabilidade". Este respondente alega ter entrado em contato com o Design Inclusivo por demanda de pesquisa (como pesquisador) e declara ensinar (ou já ter ensinado) e pesquisar (ou já ter pesquisado) essa abordagem de projeto, mas não a aplica em seus projetos profissionais.

Tanto esta resposta: "design que inclua pessoas com necessidades especiais", quanto esta: "projetos que facilitam a vida de pessoas limitadas" são respostas vagas, que podem ser consideradas como parte do que esta abordagem é capaz, mas a define. A primeira resposta vem de um respondente que diz tem aprendido sobre o Design Inclusivo em aulas na universidade (enquanto aluno), já a outra resposta vem de um professor que teve contato com o Design Inclusivo por demanda acadêmica. Ambos atuam no mercado de trabalho e na área acadêmica e não aplicam o Design Inclusivo em seus projetos profissionais.

E ainda, percebe-se, além da associação dessa abordagem com soluções destinadas às pessoas com diferenças funcionais, uma critica quanto à prática entendida pelo respondente: "Acho bonito na teoria, é legal, fofinho. Mas não se aplica ao mercado. $\mathrm{O}$ empresariado quer maximizar os lucros e não incluir as pessoas com necessidades especiais. O ROI (Return of Investment) de produtos com acessibilidade é complicado." Este respondente disse que aprendeu sobre o Design Inclusivo em aulas na universidade (enquanto aluno), atua somente no mercado e declarou não o aplica-lo em seus projetos profissionais.

Em contrapartida, a resposta a seguir mostra a $16^{\circ}$ Ergodesign - Congresso Internacional de Ergonomia e Usabilidade de Interfaces Humano Tecnológica: Produto, Informações Ambientes Construídos e Transporte

$16^{\circ}$ USIHC - Congresso Internacional de Ergonomia e Usabilidade de Interfaces Humano Computador

CINAHPA | 2017 - Congresso Internacional de Ambientes Hipermídia para Aprendizagem. necessidade percebida pelo respondente, que vai a busca do conhecimento: "Ao projetar levar em consideração que cada usuário pode ter suas próprias limitações. Geralmente as pessoas criam objetos/peças gráficas para semelhantes (ou seja, para pessoas que provavelmente não tem nenhum tipo de deficiência). Eu por exemplo nunca pensei em como um daltônico enxergaria os meus desenhos. Só me dei conta disso a partir do momento em que comecei a abordar (de leve) esse assunto em sala de aula, porém sei que preciso ler mais sobre o tema." Nota-se um ponto interessante levantado por este respondente quando diz que geralmente designers desenvolvem projetos para usuários com o perfil semelhante ao deles, pois fica clara a crítica deste respondente quanto ao "achismo" do designer e no não engajamento do usuário no processo de criação. Outro ponto relevante desta resposta é que o respondente diz que só percebeu a necessidade de mudança projetual quando compreendeu a abordagem do Design Inclusivo.

Este último respondente declara ter tido o primeiro contato com o Design Inclusivo na universidade (enquanto aluno), mas observa-se em sua fala que só se deu conta de sua importância quando começou o abordar em sala de aula como professor. Ele afirma também que o ensina (ou já ensinou) em suas aulas, mas não o aplica em seus projetos profissionais. Logo, esta é uma realidade que se repete entre alguns dos respondentes, o real conhecimento e a não aplicação.

Cabe colocar que por mais que tenhamos pessoas que compreendem o Design Inclusivo de forma congruente, ainda existem pessoas com visões contestáveis. Essas pessoas que evidenciaram o equívoco afirmaram conhecer o Design Inclusivo, sendo assim, cabe questionar se a fonte de informação dessa abordagem foi clara ou se é resultado de opiniões particulares. Portanto, fica claro que a compreensão da filosofia, do objetivo e da prática do Design Inclusivo é fundamental para que não haja mais equívocos e para que a mudança projetual aconteça de fato no mercado profissional.
Realização:

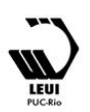




\section{$16^{\circ}$ \\ ERGODESIGN USIHC CINAHPA}

\section{0 real objetivo do Design Inclusivo}

Como exposto, há equívocos relacionados à maneira como se ensina o Design Inclusivo e ao que se compreende como sendo ele. Estes desacertos estão ligados intrinsecamente ao ensino da teoria e da prática dessa abordagem. À vista disso, cabe, como tentativa de iniciar uma mudança, o esclarecimento do real objetivo dessa abordagem.

O CUD da Universidade Estadual da Carolina do Norte deixa claro que essa abordagem de projeto percorre o âmbito da acessibilidade e sugere fazer todos os elementos e espaços acessíveis e utilizáveis por todas as pessoas, na medida do possível. Isso é realizado por meio do planejamento e do design inteligente em todas as fases de qualquer projeto. Não há a necessidade do aumento de custos, nem de resultar em instalações especiais. O Desenho Universal (Design Inclusivo) exige uma compreensão e consideração da ampla gama de habilidades humanas ao longo da vida. A aplicação criativa do conhecimento resulta em produtos e ambientes utilizáveis pela maioria das pessoas, independentemente de sua idade, agilidade, capacidades físicas ou sensoriais. [CUD, 2006]

Ao incorporar as características necessárias para as pessoas com diferenças funcionais na concepção de produtos corriqueiros, tornando-os mais fáceis e seguros para todos em sua utilização, podem-se torná-los também mais amplamente comercializáveis e rentáveis. [CUD, 2006]

Diante do que foi dito, produtos inclusivos podem ampliar a gama de usuários/consumidores, beneficiando não só a sociedade, como também a empresa que optar por projetar dessa forma. Entende-se que o investimento deve estar no estudo das diversidades humanas, suas características, vivências e necessidades, não em recursos custosos. Partindo da inserção desse conhecimento na concepção do projeto, soluções serão geradas prevendo as diferentes formas de uso como requisitos de projeto.

Visto o conceito errôneo que muitas pessoas têm $16^{\circ}$ Ergodesign - Congresso Internacional de Ergonomia e Usabilidade de Interfaces Humano Tecnológica: Produto, Informações Ambientes Construídos e Transporte

$16^{\circ}$ USIHC - Congresso Internacional de Ergonomia e Usabilidade de Interfaces Humano Computador

CINAHPA | 2017 - Congresso Internacional de Ambientes Hipermídia para Aprendizagem.

definindo o Design Inclusivo como projetos destinados às pessoas com diferenças funcionais, é fundamental romper com esse estereótipo o distanciando da acessibilidade. Isto posto, cabe colocar que ele não é resultante de uma atitude de solidariedade destinada somente às $\mathrm{PcD}$, ao passo que objetiva simplificar e facilitar a vida de todos, ampliando a forma de uso de um produto e proporcionando diferentes formas de executar uma tarefa.

No âmbito da responsabilidade social, leis e declarações tonificam a obrigação de incluir a todos de forma igualitária na participação social, abarcando trabalho, estudo e lazer - em especial, o artigo $1^{\circ}$ da Declaração Universal dos Direitos Humanos [1948], enunciada pela Organização das Nações Unidas (ONU), e o artigo $5^{\circ}$ da Constituição da República Federativa do Brasil [1988]. Tanto a Declaração Universal quanto a lei brasileira salientam o equilíbrio da sociedade com o cumprimento dos direitos igualitários à vida, à liberdade, à segurança e à propriedade. Outras leis foram criadas a favor da acessibilidade e da inclusão social no Brasil, porém, as leis que salientamos neste artigo são prescrições básicas destinadas, incontestavelmente, a toda a população.

Contudo, fica claro que pensar em Design Inclusivo não é um ato de benevolência, é um ato de cidadania, atitude essa de um profissional que se utiliza de suas expertises para corroborar o direito de todos. Uma vez que empresas lutam para se destacarem em meio à competição ferrenha pela inovação, gerar produtos inclusivos não é só se diferenciar, mas oferecer oportunidades mais justas em relação à autonomia ativa diante da sociedade. O motivo que fortalece o uso do Design Inclusivo em projetos de produto de uso cotidiano é a promoção de uma vida mais ativa e independente para as pessoas com diferenças funcionais, favorecendo um uso mais prático centrado nas habilidades humanas.

Na vida, possivelmente todas as pessoas passarão por alguma limitação, momentânea ou temporária, e isso justifica a necessidade de produtos que facilitem o uso prevendo as possíveis dificuldades que pessoas com ou sem diferenças funcionais. 


\section{$16^{\circ}$ \\ ERGODESIGN USIHC CINAHPA}

Entendendo que essa abordagem visa atender ao máximo de usuários possíveis, ela se encaixa nesse conceito, considerando os limites de cada projeto, a diversidade humana e as diferentes formas de uso.

Clarkson \& Coleman [2015] afirmam que o Design Inclusivo se baseia em algumas concepções. Primeiramente, acredita-se que há muita diversidade considerável na capacidade mental e física entre a população, além de não ser aceitável a associação entre "normalidade" e "fisicamente apto", ou seja, uma pessoa com o corpo forte e saudável. Em segundo lugar, a deficiência é resultado de interações com o ambiente projetado e das intervenções estruturais, e não inerente a níveis de capacidade, estado de saúde ou graus associados de imparidade do usuário.

Esta última afirmação de Clarkson \& Coleman pode ser reforçada com uma frase presente no relato de um homem que se locomove através de cadeira de rodas em uma entrevista publicada por Globo.com: "Eu só percebo a minha deficiência quando falta acessibilidade" [GLOBO.COM, 2015]. Certamente o indivíduo com alguma deficiência se reconhece em suas condições normais e só se sente incapaz diante das barreiras encontradas ao seu redor.

Portanto, a deficiência é vista como normalidade diante das condições humanas. Para reforçar o que foi dito, Coleman [1994] nos assegura que a humanidade é vulnerável em algumas situações e com isso capaz de compensar estendendo suas habilidades pelo uso de próteses, que são elegantes e eficazes. O autor cita exemplos, como: as roupas que usamos para manter e regular nosso calor do corpo e para transmitir mensagens sociais complexas; os microfones que usamos para amplificar nossas vozes; e as cadeiras para apoiar nosso peso quando estamos cansados de ficar em pé. Em termos de autoestima e design, não há nenhum problema em sentir a necessidade de utilizar os produtos citados. [COLEMAN, 1994]

As mulheres grávidas podem sentir-se em algum momento incapazes diante de algumas atividades, e homens jovens que sofrem de uma lesão $16^{\circ}$ Ergodesign - Congresso Internacional de Ergonomia e Usabilidade de Interfaces Humano Tecnológica: Produto, Informações Ambientes Construídos e Transporte

$16^{\circ}$ USIHC - Congresso Internacional de Ergonomia e Usabilidade de Interfaces Humano Computador

CINAHPA | 2017 - Congresso Internacional de Ambientes Hipermídia para Aprendizagem. esportiva também se sentirão menos capazes de exercer algumas ações. À vista disso, no que diz respeito ao curso de vida como um todo, devemos reconhecer que a deficiência é uma experiência universal, e que os períodos de incapacidade que todos nós vivenciamos, portanto, devem ser considerados normais. Se estendermos nossa compreensão da normalidade para incluir todos os eventos em um ciclo de vida, nem envelhecimento nem deficiência em seu sentido amplo são excluídos da experiência normal. [COLEMAN, 1994]

Diante disso, investir em produtos inclusivos não requer necessariamente custos elevados, mas exige que o profissional tenha conhecimento vasto de todo o contexto de uso que um produto pode ter. Esse investimento resultará em uma ampla gama de consumidores ativos. O designer carrega em si uma responsabilidade diante das atividades diárias das pessoas, atributo esse capaz de excluir ou incluir. Portanto, percebe-se a importância desse profissional para a construção de um mundo com mais qualidade de vida.

Compreende-se que um produto carrega em si uma responsabilidade imensa. Segundo Clarkson \& Coleman [2015], se os produtos são considerados em termos das demandas de capacidade que eles esperam do usuário, então será possível mostrar partes da população como ativadas e desativadas de acordo com o nível de capacidade exigido pelo produto. Nesse caso, o cenário da demanda de capacidade torna-se parte do processo de tomada de decisão do design. Os autores recomendam que projetistas devem "entender melhor as capacidades dos usuários e criar interfaces intuitivas, embalagens de fácil abertura, bem-estruturadas, sinalização lógica e clara, direção assistida e frenagem. E projetos modulares e personalizáveis podem melhorar muito a usabilidade"

[CLARKSON; COLEMAN, 2015, p. 236, tradução nossa].

Em suma, vivemos em um mundo cada vez mais moldado pela intervenção humana, em que o design pode habilitar ou desabilitar as pessoas. É crucial que projetemos um mundo que corresponda melhor à diversidade presente no seio da

Realização:




\section{$16^{\circ}$ \\ ERGODESIGN USIHC CINAHPA}

$16^{\circ}$ Ergodesign - Congresso Internacional de Ergonomia e Usabilidade de Interfaces Humano Tecnológica: Produto, Informações Ambientes Construídos e Transporte

$16^{\circ}$ USIHC - Congresso Internacional de Ergonomia e Usabilidade de Interfaces Humano Computador

CINAHPA | 2017 - Congresso Internacional de Ambientes Hipermídia para Aprendizagem. população. [CLARKSON; COLEMAN, 2015]

\section{Limites e amplitudes}

O Design Inclusivo não é global. Não cabe desprezar as diferenças de gostos, culturas e etnias. $\mathrm{Na}$ elaboração de um produto inclusivo, deve-se estudar a preferência do público destinatário, por mais ampla que seja. Essa etapa do projeto está intrínseca à atividade do designer, pois em qualquer projeto elaborado por ele há o estudo da cultura, do repertório e do gosto dos usuários. Qualquer produto apresenta características atrativas para um público específico, e um produto inclusivo não se apresenta de modo diferente; a distinção está em considerar o maior número de repertórios e vivências possíveis.

O principal foco do Design Inclusivo não está em agradar a "gregos e troianos", visto que a diferença de cultura influencia as características que agradam ou não, que comunicam ou não, que produzem uma relação afetiva ou não. Essa diferença cultural deve ser considerada no estudo do destinatário de qualquer projeto. $\mathrm{O}$ foco dessa abordagem de projeto está em atender "gregos e troianos", visto que os seres humanos são constituídos por restrições e habilidades em qualquer lugar do mundo, sendo a ideia fazer com que uns e outros utilizem um produto sem nenhuma dificuldade.

Um projeto inclusivo exige o conhecimento de todos os possíveis usuários e de como o produto poderia ser utilizado. Dischinger [2012] afirma que o real desafio na elaboração de projetos inclusivos é "desenvolver ações de projeto que conciliem necessidades diversas e complexas, reconhecendo que as pessoas são naturalmente diferentes". [DISCHINGER, 2012, p. 16] Não obstante, pode haver limites na utilização, pois cada objeto requer um contexto de uso, ora ampliado ao máximo de usuários, ora considerando somente alguns. Em suma, atender ao maior número de pessoas depende dos limites do produto em si, da amplitude da pesquisa e da imersão em vivências diversas.

Uma questão levantada por Guilhermo [1995] é que "o Design deveria ser universal por excelência". O designer por si já deveria prever a exclusão que o produto criado causaria. Um projeto direcionado para um público específico (por exemplo, um público com habilidades favoráveis ao uso) exclui as pessoas que não têm tais características, mas que também utilizam o artefato. O Design Inclusivo é o design que conhecemos em sua forma ampla de ser, com público ampliado, com mais requisitos de projeto, mais pesquisas e mais repertórios envolvidos.

A consequência da ampliação de público é o número maior de problemas que serão encontrados, tendo como objetivo cercar todas as questões problemáticas que um produto pode apresentar em seu uso, resultando em uma visão holística do uso. Proporcionar soluções para a variedade de problemas encontrados é produzir um design completo, uma solução total. O termo "holístico" deriva de holos, que em grego significa "todo" ou "inteiro". O holismo é um conceito criado por Jan Christiaan Smuts [1926], que o descreveu como a "tendência da natureza de usar a evolução criativa para formar um 'todo' que é maior do que a soma das suas partes".

A princípio, o ideal é ter um enfoque sistêmico, ou seja, propor ao designer uma nova forma de pensar: o conjunto são as partes que compõem o todo, e é o todo que determina o comportamento das partes. Entendendo as partes como as diversas formas de uso, contendo as várias habilidades específicas encontradas por pessoas com diferentes necessidades e situações, e o todo como o produto que abarca o uso em diferentes circunstâncias, a solução se torna inclusiva.

É importante que os projetistas busquem conhecer casos específicos, pontos críticos e situações de conflito para enriquecer a visão do todo, buscando, assim, uma visão mais completa do problema de uso. As soluções são ao mesmo tempo especialistas e generalistas. Especialistas porque consideram uma forma de uso específica, uma habilidade oriunda da necessidade ou da limitação peculiar de um grupo menor, que pode ser em algum momento da vida também de um grupo maior. Generalistas porque abarcam um vasto campo de possibilidades de uso e de contextos.
Realização:

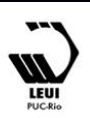




\section{$16^{\circ}$ \\ ERGODESIGN USIHC CINAHPA}

O desafio é exaltar as habilidades, e não as limitações. A proposta é partir das dificuldades permanentes ou momentâneas dos usuários para procurar explorar as habilidades não prejudicadas. Portanto, é preciso conhecer os problemas de uso e as restrições dos usuários, mas são as habilidades que guiarão as soluções dos projetistas. Como exemplo, em um contexto de uso no qual há uma limitação visual, seja ela causada por uma patologia do indivíduo, uma deficiência congênita ou uma restrição momentânea - como uma pessoa aparentemente sem "problemas visuais" em um lugar escuro tendo de utilizar um produto duas das habilidades favoráveis são a audição e o tato; portanto, nesse contexto uma das formas de solução é explorar essas habilidades.

Repetidas vezes foi elucidado que o conceito do Design Inclusivo abraça a diversidade como filosofia e ideal, portanto, pode-se dizer que este é centrado no humano e nas habilidades funcionais que existem no conjunto de usuários que compõe a humanidade. Para ilustrar essa característica, propõe-se uma estrutura de pensamento representada por formas orgânicas, as quais sofrem alterações de acordo com a demanda e a limitação de cada projeto. Essa ideia se configura da seguinte forma, representada na Figura 01:

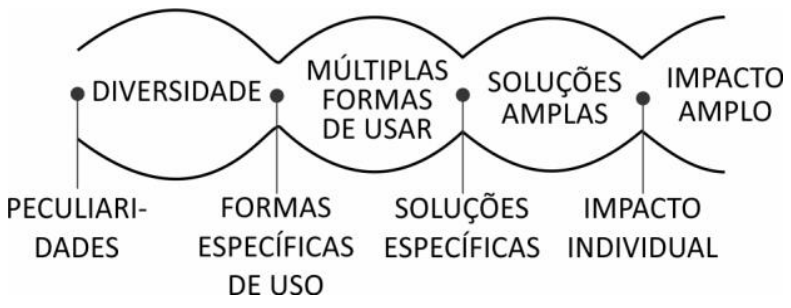

Fig. 01: Estrutura ilustrativa do pensamento do Design Inclusivo. Produzida pelo autor.

O Design Inclusivo parte das peculiaridades, das características limitantes de grupos específicos para contribuir com a diversidade; ele reconhece formas específicas de uso colecionando múltiplas formas de utilizar um objeto; ele apresenta soluções específicas para grupos específicos de usuários e soluções mais amplas para uma quantidade maior de usuários. O Design Inclusivo visa causar um impacto benéfico na vida do indivíduo com limitações peculiares, além de $16^{\circ}$ Ergodesign - Congresso Internacional de Ergonomia e Usabilidade de Interfaces Humano Tecnológica: Produto, Informações Ambientes Construídos e Transporte

$16^{\circ}$ USIHC - Congresso Internacional de Ergonomia e Usabilidade de Interfaces Humano Computador

CINAHPA | 2017 - Congresso Internacional de Ambientes Hipermídia para Aprendizagem.

causar um impacto benéfico no uso de produtos por um grupo maior de usuários, aumentando a praticidade. $\mathrm{O}$ impacto atinge de forma positiva a sociedade com a promoção da autonomia e o aumento de pessoas ativas.

\section{Conclusão}

Retomando a problemática apresentada, foi possível observar equívocos no ensino do Design Inclusivo nos cursos brasileiros de graduação em Design. O fato é que essa abordagem permeia o meio acadêmico e a principal fonte de conhecimento dela é a universidade. Não obstante, pôde-se observar que os processos projetuais mais ensinados pelos professores respondentes nem sempre fundamentam uma prática centrada no usuário e tampouco favorece a diversidade funcional.

Além disso, por mais que existam professores que o ensina, há ainda muitos designers que acreditam que o conhece, mas não compreendem a sua filosofia. Não ter uma disciplina que aborde integralmente a teoria e a prática do Design Inclusivo, sendo ele apenas citado em alguns momentos ou até mesmo ensinado superficialmente, faz com que o conhecimento adquirido seja da mesma forma, superficial e dando margem para interpretações equivocadas.

Acredita-se na importância de desvincula-lo ao tema da deficiência e atrela-lo às barreiras que os produtos podem conceber a quaisquer usuários, às dificuldades que se podem ter no uso de produtos em certos contextos. Entende-se, também, que o ensino do Design Inclusivo deve ser isolado de qualquer outra disciplina relacionada a Acessibilidade e Tecnologia Assistiva e deve, preferencialmente, estar integrado a disciplina de projeto.

Contudo, acredita-se que reconhecer a filosofia do Design Inclusivo é um passo importante rumo a sua maior adoção por profissionais de mercado e que a propagação do conhecimento entorno da teoria e prática dessa abordagem deve vir do ensino universitário. Por acreditar na capacidade dos professores em formar profissionais 


\section{$16^{\circ}$ \\ ERGODESIGN USIHC CINAHPA}

conscientes e preparados para atuar é que se concebe esta afirmação. Se um dos objetivos das universidades é preparar o aluno para atuar e se destacar no mercado, nada mais junto que a adoção do Design Inclusivo comece por lá. Sendo assim, estima-se que este artigo seja uma parte sucinta de tudo o que pode ser estudado e construído pela perspectiva do Design Inclusivo na extensa área do Design.

\section{BIBLIOGRAFIA}

BRASIL. Constituição da República Federativa do Brasil : texto constitucional promulgado em 5 de outubro de 1988, com as alterações adotadas pelas Emendas Constitucionais nos 1/1992 a 68/2011, pelo Decreto Legislativo no 186/2008 e pelas Emendas Constitucionais de Revisão nos 1 a 6/1994. - 35. ed. - Brasília : Câmara dos Deputados, Edições Câmara, 2012.

\section{Declaração Universal dos Direitos}

Humanos. Adotada e proclamada pela resolução 217 A (III) da Assembléia Geral das Nações Unidas em 10 de dezembro de 1948.

CLARKSON, P. John; COLEMAN, Roger. History of inclusive design in the UK. Applied Ergonomics, v. 46, p. 235-247, 201./abr. 2017.

COLEMAN, R., 1994. The Case for Inclusive Design e an Overview, 12th Triennial Congress. International Ergonomics Association and the Human Factors Association of Canada, Toronto, Canada.

DEFICIENTE CIENTE. Deficiente ciente - o blog da inclusão e cidadania. Disponível em: $<$ https://www.deficienteciente.com.br/>. Acesso em: 10 ago. 15 .

DESIGN COUNCIL. A study of the design process. Disponível em :

<http://www.designcouncil.org.uk/>. Acesso em: 10 jan. 2017.

DISCHINGER, Marta. Promovendo acessibilidade espacial nos edifícios públicos: Programa de Acessibilidade às Pessoas com Deficiência ou Mobilidade Reduzida nas $16^{\circ}$ Ergodesign - Congresso Internacional de Ergonomia e Usabilidade de Interfaces Humano Tecnológica: Produto, Informações Ambientes Construídos e Transporte

$16^{\circ}$ USIHC - Congresso Internacional de Ergonomia e Usabilidade de Interfaces Humano Computador

CINAHPA | 2017 - Congresso Internacional de Ambientes Hipermídia para Aprendizagem.

Edificações de Uso Público / Marta Dischinger, Vera Helena Moro Bins Ely, Sonia Maria Demeda Groisman Piardi. - Florianópolis: MPSC, 2012.

\section{GUILHERMO, A., Acessibilidade e Design}

Universal. Anais eletrônicos. Laboratório ADAPTSE. Escola de Arquitetura da Universidade Federal de Minas Gerais, 1995. Acesso em 25 de jun. de 2015. Endereço eletrônico: <http://www.adaptse.org/17323>. Acesso em: 25 de jul. 2013.

MONT'ALVÃO, C. R.; VILLAROUCO, V. (Org.). Um novo olhar para o projeto: a ergonomia no ambiente construído. 1. ed. Teresopolis, RJ: $2 \mathrm{AB}$, 2011. V.1. 184p.

\section{Agradecimentos}

Agradeço ao Conselho Nacional de Desenvolvimento Científico e Tecnológico (CNPq) pelo auxílio à pesquisa realizada. 